\title{
JM
}

Volume 6 No. 1 (April 2018)

(C) The Author(s)

\section{GAMBARAN PENGETAHUAN DAN PENDIDIKAN TENTANG KEIKUTSERTAAN SUAMI MENJADI AKSEPTOR KB DI WILAYAH PUSKESMAS KAMPUNG BALI KOTA BENGKULU}

\author{
THE DESCRIPTION OF KNOWLEDGE AND EDUCATION ABOUT HUSBANDS \\ PARTICIPATION TO BE FAMILY PLANNING ACCEPTORS \\ AT KAMPUNG BALI PHC IN BENGKULU
}

\author{
SYAMI YULIANTI \\ DOSEN PRODI DIPLOMA III KEBIDANAN FIKES UNIVED BENGKULU \\ Email : syamiyulianti@gmail.com
}

\begin{abstract}
ABSTRAK
KB (Keluarga Berencana) merupakan suatu cara yang efektif untuk menghentikan tingginya laju pertumbuhan penduduk, jumlah penduduk di Indonesia pada tahun 2013 sebesar 248.422.956 jiwa jumlah tersebuit meningkat dengan relatif cepat. Di perlukan kebijakan untuk mengatur atau membatasi jumlah kelahiran agar kelahiran dapat di kendalikan, persentase pemakaian alat kontrasepsi pada pasangan usia subur (PUS) khususnya suami yaitu AKDR (3,5\%), Implan (4,3\%), MOP (0,1\%), MOW (2,3\%), Pil (13,9\%), Suntik $(34,3)$, Kondom $(0,8 \%)$, dan Alamiah (0,3\%). Masih sedikit presentase yang menggunakan kontrasepsi pria. Tujuan Penelitian untuk mengetahui gambaran pengetahuan dan pendidikan tentang keikutsertaan suami menjadi akseptor KB di wilayah Puskesmas Kampung Bali Kota Bengkulu. Metode Penelitian deskriptif dengan tehnik accidental sampling, jumlah sampel 100 orang pasangan usia subur khususnya suami pada tanggal 08 Januari 2015 di Wilayah Puskesmas Kampung Bali Kota Bengkulu. Hasil Penelitian menunjukkan bahwa sebagian besar (61\%) responden mempunyai tingkat pengetahuan kurang dan sebagian besar (71\%) berpendidikan yang rendah. Kesimpulan yang dapat diambil dari penelitian ini adalah tingkat pengetahuan dan pendidikan suami di wilayah puskesmas kampung bali kota bengkulu tentang keikutsertaan suami menjadi akseptor KB masih tergolong rendah. Saran diharapkan sebagai tenaga kesehatan supaya dapat memberikan informasi yang lebih baik tentang KB terutama kondom dan MOP supaya persentasi $\mathrm{KB}$ kondom dan MOP meningkat supaya bisa menekan laju pertumbuhan penduduk yang semakin meningkat.
\end{abstract}

Kata Kunci : Pengetahuan, Pendidikan.

\begin{abstract}
KB (Family Planning) is an effective way to stop the high rate of population growth, the number of people in Indonesia in 2013 amounted to 248422 956, those inhabitants number increases relatively quickly. The need policies to regulate or limit the number of birth can be addressed births, the percentage of couples use contraception at fertile age (EFA) especially husband was the IUD (3.5\%), implants (4.3\%), MOP (0.1\%), MOW (2.3\%), pills $(13.9 \%)$, injections (34.3), condoms (0.8\%), and Natural (0.3\%). Male contraception percentage is still low. Objective To know the knowledge and education about the husband's participation become
\end{abstract}


family planning acceptors in Kampung Bali PHC in the city of Bengkulu. The research was a descriptive with accidental sampling technique, the number of samples used were 100 couples of childbearing age especially husbands on January 8, 2015 at Kampung Bali PHC in the city of Bengkulu. The results of this research indicated that the majority $(61 \%)$ of respondents had less knowledge level and most (71\%) were lower educated. Conclusions that can be drawn from this research was the husband's level of knowledge and education in the area of Kampung Bali PHC in Bengkulu city on the participation of a husband being acceptors was still relatively low. Suggestion: it is expected the health workers to provide better information about family planning, especially the use of condoms KB and MOP to reduce the rate of population growth.

Keywords: Knowledge, Education.

\section{PENDAHULUAN}

Masalah utama yang sedang dihadapi negara-negara yang sedang berkembang seperti Indonesia adalah masih tingginya laju pertumbuhan penduduk dan kurang seimbangnya penyebaran dan struktur umur penduduk keadaan penduduk yang demikian telah mempersulit usaha peningkatan dan pemerataan kesejahteraan rakyat. Semakin tinggi pertumbuhan penduduk semakin besar usaha yang diperlukan untuk mempertahankan tingkat tertentu kesejahteraan rakyat . Jumlah penduduk di Indonesia pada tahun 2013 sebesar 248.422.956 jiwa, jumlah tersebut, meningkat dengan relatif cepat, diperlukan kebijakan untuk mengatur atau membatasi jumlah kelahiran agar kelahiran dapat dikendalikan(Depkes, 2013).

Berdasarkan data dari Depkes RI 2013 jumlah PUS sebanyak 45.972.185 jiwa dengan peserta $\mathrm{KB}$ aktif sebesar 35.276.105 orang, presentase pemakaian alat kontrasepsi AKDR (3,5\%), Implant (4,3\%), MOP (0,1\%), MOW (2,3\%), Pil (13,9\%), Suntik (34,3\%), Kondom $(0,8 \%)$ dan metode alamiah $(0,3 \%)$. Berdasarkan data diatas dapat di lihat masih rendahnya partisipasi pria dalam ber-KB hal ini disebabkan oleh berbagai aspek yang bisa berasal dari sisi klien pria itu sendiri yaitu: pengetahuan, sikap, dan kebutuhan yang ia inginkan, sedangkan faktor lingkungan meliputi: ekonomi, sosial budaya, keterbatasan informasi tentang kontrasepsi laki-laki (Depkes, 2013).

Rendahnya keikutsertaan pria dalam ber-KB dapat memberikan dampak negatif bagi kaum wanita dalam kesehatan reproduksi, tidak hanya kaum wanita saja yang selalu berperan aktif, tetapi pria juga harus ikut berpartisipasi dalam mengurangi kesakitan ibu (Manuaba, 2010).

Pengetahuan tentang $\mathrm{KB}$ sangatlah penting untuk dimiliki oleh akseptor dalam memilih alat kontrasepsi yang akan dipergunakan karena pengetahuan merupakan domain yang sangat penting dalam membentuk prilaku seseorang. Banyak suami yang mengalami kesulitan dalam menetukan pilihan jenis kontrasepsi. Hal ini tidak hanya karena terbatasnya metode yang tersedia, tetapi juga oleh ketidaktahuan mereka tentang kemampuan metode kontrasepsi tersebut (Notoatmodjo, 2010).

\section{TUJUAN PENELITIAN}

Untuk diketahuinya Gambaran Pengetahuan dan Pendidikan Tentang Keikutsertaan Suami Menjadi Akseptor KB di Wilayah Puskesmas Kampung Bali Bengkulu

\section{METODE PENELITIAN}

Jenis penelitian yang dilakukan pada penelitian ini adalah metode deskriptif yaitu suatu metode penelitian yang dilakukan dengan tujuan membuat gambaran atau deskriptif tentang suatu keadaan secara objektif (Notoatmodjo, 2010). Dalam penelitian ini peneliti menggunakan tingkat pengetahuan suami Tentang Alat Kontrasepsi Pria Ditinjau dari Pengetahuan dan Pendidikan di Wilayah Puskesmas Kampung Bali Kota Bengkulu. Populasi dalam 
penelitian adalah seluruh PUS khususnya suami di Wilayah Puskesmas Kampung Bali Bengkulu yang berjumlah 1.733 orang. Sampel yang diambil menggunakan tehnik accidental sampling yaitu sampel yang kebetulan pada saat penelitian. Sampel yang digunakan dihitung menggunakan rumus perhitungan sehingga sampel dalam penelitian ini sebesar 100 orang.

\section{HASIL PENELITIAN}

Tabel 1. Distribusi Frekuensi Tingkat Pengetahuan dan pendidikan Suami Menjadi Akseptor KB di Puskesmas Kampung Bali Kota Bengkulu

\begin{tabular}{cccc}
\hline No & Variabel & $\begin{array}{c}\text { Frekuensi } \\
\text { (f) }\end{array}$ & $\begin{array}{c}\text { Presentase } \\
(\mathbf{\%})\end{array}$ \\
\hline & Pengetahuan & & \\
\hline \multirow{2}{*}{1} & Baik & 19 & 19 \\
\cline { 2 - 4 } & Cukup & 20 & 20 \\
\cline { 2 - 4 } & Kurang & 61 & 61 \\
\hline & Jumlah & $\mathbf{1 0 0}$ & $\mathbf{1 0 0}$ \\
\hline \multirow{3}{*}{2} & Pendidikan & & \\
\cline { 2 - 4 } & Tinggi & 13 & 13 \\
\cline { 2 - 4 } & Menengah & 16 & 16 \\
\hline & Rendah & 71 & 71 \\
\hline
\end{tabular}

Dari tabel 1 diatas dapat diketahui dari 100 responden sebagian besar (61\%) responden mempunyai tingkat pengetahuan kurang dan sebagian besar (71\%) berpendidikan yang rendah.

\section{PEMBAHASAN}

\section{a. Gambaran Pengetahuan tentang Keikutsertan Suami Menjadi Akseptor KB di Wilayah Puskesmas Kampung Bali Kota Bengkulu}

Berdasarkan hasil analisis dalam penelitian ini, didapatkan bahwa dari 100 orang suami menjadi akseptor KB di wilayah puskesmas Kampung Bali Bengkulu, menunjukan bahwa sebagian kecil $(19,0 \%)$ suami memiliki pengetahuan baik dalam menjadi akseptor KB, sebagian kecil $(20,0 \%)$ suami memiliki pengetahuan cukup dan sebagian besar $(61,0 \%)$ suami memiliki pengetahuan kurang.

Pada penelitian ini dari hasil wawancara sebagian besar $(61,0 \%)$ suami memiliki pengetahuan kurang disebabkan masih rendahnya keikutsertaan suami dalam menggunakan alat kontrasepsi dan mengikuti program KB dikarenakan kurangnya minat pria untuk mengikuti program KB. Kurangnya minat pria menggunakan metode kontrasepsi disebabkan oleh ketidak nyamanan suami saat melakukan senggama. Hal ini sejalan dengan teori Mubarak (2010), ada beberapa faktor yang mempengaruhi pengetahuan salah satunya adalah minat, minat menjadikan seseorang untuk mencoba dan menekuni suatu hal dan pada akhirnya diperoleh pengetahuan yang mendalam.

Rendahnya pengetahuan bisa saja menjadi salah satu penyebab suami tidak ingin menggunakan alat kontrasepsi pria, suami tidak mengetahui secara tepat dan jelas alat kontrasepsi pria, bagaimana cara kerja, apa efek samping nya, sehingga suami tidak ingin memilih alat kontrasepsi pria karena dianggap berbahaya (Hurlock, 2009).

Menurut Hartanto (2007) salah satu faktor yang mempengaruhi pengetahuan seseorang adalah pendidikan. Maka makin tinggi pendidikan seseorang, makin tinggi pula pengetahuan dimilikinya, sehingga makin muda dalam menerima berbagai informasi. begitu juga sebaliknya, pendidikan yang kurang akan menghambat perkembangan sikap seseorang terhadap informasi ataupun nilai-nilai baru yang diperkenalkan.

Faktor pengetahuan ini memegang peran yang penting dalam melakukan perilaku-perilaku kesehatan yang baik, salah satunya adalah dalam keikutsertaan suami menjadi akseptor KB. Dengan adanya pengetahuan dan pendidikan mendorong kemampuan dan kemauan yang ditujukan kepada suami. Sehingga orang yang memiliki pengetahuan yang tinggi akan mampu memahami arti hidup, mampu menjalani 
hidup lebih terarah, adanya masalah yang muncul dalam dirinya mampu dikelola dengan dengan pemikiran yang lebih rasional (Hartanto, 2007).

Menurut Azwar (2007), fungsi pengetahuan yang mendorong untuk manusia untuk ingin tahu, untuk mencari penalaran, dan untuk mengorganisasikan pengalamanya. Begitu pula pada penelitian ini suami yang memiliki pengetahuan yang baik tentang pentingnya keikutsertaan suami menjadi akseptor KB, pada umumnya akan menggunakan alat kontrasepsi pria.

Hasil penelitian ini sejalan dengan hasil penelitian Ekarini (2008) dengan judul "Gambaran Partisipasai Pria Terhadap Pemilihan Alat Kontrasepsi Keluarga di Wilayah Kerjah Puskesmas Kandang Kota Bengkulu" yang hasilnya menunjukan bahwa partisipasi pria dalam pemilihan alat kontrasepsi masih rendah.

Dampak dari kurangnya pengetahuan suami mengenai alat kontrasepsi pria adalah timbulnya keraguan dan ketakutan pada suami untuk memilih alat kontrasepsi pria. Jika ibu belum mempunyai keputusan, oleh karena ketidaktahuan tentang informasi kontrasepsi yang tepat digunakan oleh suami, dengan menggunakan beberapa artenatif sehingga dapat memilih sesuai dengan pengetahuan dan keyakinan yang dimiliki.

\section{b. Gambaran Pendidikan Keikutsertaan Suami Menjadi Akseptor KB di Wilayah Puskesmas Kampung Bali Kota Bengkulu}

Berdasarkan hasil penelitian ini, diketahui bahwa 13 responden yang berpendidikan tinggi seluruh responden (100\%) berpengetahuan baik, sebagian besar dari responden $(61 \%)$ berpengetahuan kurang dengan pendidikan tinggi maka seseorang akan cenderung untuk mendapatkan informasi yang masuk semakin banyak pula pengetahuan tentang alat kontrasepsi pria yg didapatnya.

Hampir seluruh responden (71\%) berpendidikan rendah memiliki pengetahuan kurang. Menurut Hartanto (2007), semakin tinggi tingkat pendidikan seseorang maka semakin tinggi pula motivasi untuk memanfaatkan fasilitas kesehatan karena telah memiliki pengetahuan dan wawasan yang lebih luas. Dengan kata lain, melalui pendidikan seseorang akan mengalami proses pembelajaran yang selanjutnya akan mempengaruhi perilaku seseorang dalam melakukan tindakan pemeliharaan, dan peningkatan kesehatan, serta dapat membuat keputusan yang lebih baik dalam bertindak. Dengan demikian, makin tinggi pendidikan seseorang, maka makin tinggi pula keinginan dan kesadaran seseorang, khususnya keikutsertaan suami menjadi akseptor KB.

Pendidikan dapat mempengaruhi seseorang termasuk juga perilaku seseorang akan keputusanya terutama dalam motivasi untuk ikut berperan serta dalam pengembangan kesehatan, maka tingginya tingkat pendidikan seseorang, makin mudah menerima informasi sehingga makin banyak pula pengetahuan yang dimiliki. Sebaliknya pendidikan yang kurang akan menghambat perkembangan sikap seseorang terhadap perubahan hidup sehat. Maka tinggi rendahnya pendidikan suami sangat erat hubunganya dengan tingkat kesadaran suami dalam menggunakan alat kontrasepsi (Manuaba, 2010).

Peran pendidikan dalam bidang kesehatan adalah salah satu upaya untuk membuat perilaku masyarakat terhadap kesehatan yang artinya pendidikan kesehatan berupaya agar masyarakat menyadari dan mengetahui bagaimana cara memelihara kesehatan mereka dan kemana harus mencari pertolongan bila sakit. Pendidikan dapat mempengaruhi seseorang termasuk juga perilaku seseorang akan kepatuhan termasuk dalam motivasi untuk ikut serta dalam pembangunan kesehatan, salah satunya adalah dalam mengikuti pemilihan alat kontrasepsi (Dewi, 2010).

Pendidikan akseptor KB dipengaruhi melalui pendidikan formal dan pendidikan non formal, pendidikan formal melalui jalur pendidikan yang terstruktur dan berjenjang 
yang terdiri atas pendidikan dasar, pendidikan menengah dan pendidikan tinggi sedangakan pendidikan non formal seperti melalui promosi kesehatan melalui penyuluhan tentang alat kontrasepsi pria oleh kader atau tenaga kesehatan di posyandu atau puskesmas. Selain itu pendidikan dapat diproleh dengan cara mendengar radio, menonton televisi, dan lain-lain. Pendidikan suami yang kurang tentang pengertian alat kontrasepsi pria dapat berpengaruh pada pemilihan alat kontrasepsi, sebab pendidikan merupakan salah satu faktor yang berpengaruh terhadap perilaku kesehatan seseorang.

Hasil penelitian ini, dari 100 responden suami tidak ada yang mengikuti pendidikan non formal seperti melalui promosi kesehatan, penyuluhan tentang alat kontrasepsi pria oleh kader atau tenaga kesehatan, kelompok KB pria, Pusat Kegiatan Belajar Masyarakat (PKBM) dan lembaga pelatihan. Hal ini disebabkan karena suami sibuk dengan pekerjaan mereka. Sedangkan yang berpendidikan formal, suami hanya mendapatkan pendidikan melalui pendidikan dasar, pendidikan menengah dan pendidikan tinggi.

Hasil penelitian ini sejalan dengan penelitian yang dilakukan oleh Wulandari (2013) "Hubungan Pendidikan Terhadap Pengetahuan Akseptor KB dalam Penggunaan KB di Wilayah Kerjah Puskesmas Pasar Ikan Kecamatan Teluk Segara". Yang juga menyatakan bahwa tingkat pendidikan mempengaruhi suami dalam memilih alat kontrasepsi pria. Semakin tinggi pendidikan seseorang, maka informasi yang didapat juga semakin banyak, sehingga dapat mendorong seseorang untuk tindakan tertentu, terutama bagi suami dalam memilih alat kontrasepsi.

\section{KESIMPULAN}

Berdasarkan hasil penelitian dan pengolahan data serta pembahasan pada bab sebelumnya, maka dapat dapat ditarik kesimpulan yaitu :
1. Sebagian besar $(61.0 \%)$ suami memiliki pengetahuan yg kurang tentang alat kontrasepsi pria.

2. Sebagian besar $(71.0 \%)$ suami memiliki pendidikan yg rendah tentang alat kontrasepsi pria.

\section{SARAN}

Diharapkan hasil penelitian ini dapat digunakan bahan masukan dalam meningkatkan kualitas pelayanan KB melalui pelayanan-pelayanan dan adanya pojok konsultasi $\mathrm{KB}$ terutama $\mathrm{KB}$ pria

\section{DAFTAR PUSTAKA}

Arikunto (2006). Metodologi Penelitian Kesehatan. Jakarta: Renika Cipta.

Azwar (2008). Tingkat Pendidikan Mempengaruhi Pengetahuan. (diakses pada tanggal 06 Maret 2015). Diunduh dari : http://www.mitradialog.Com.

BKKBN (2011). Buku Panduan Praktis Pelayanan Kontrasepsi. Jakarta: Yayasan Bina Pustaka.

Dep. Kes (2009). Kontrasepsi MOP dan Kondom. (Diakses 25 Desember 2015) Diunduh dari : http: //www. Keluarga berencana.com

Dep. Kes RI (2006). Kamus Bahasa Indonesia. Balai Pustaka Indonesia.

Dewi (2010). Dasar-dasar pendidikan. Jakarta : Salemba Medika.

Din.Kes (2013). Profil Kesehatan Kota Bengkulu Tahun 2013. Bengkulu: Dinkes Kota Bengkulu.

Ekarini (2008). Gambaran Partisipasi Pria Terhadap Pemilihan Alat Kontrasepsi Keluarga di Wilayah Kerjah Puskesmas Kandang Kota Bengkulu. Bengkulu. KTI. Akademi Kebidanan Dehasen.

Hartanto (2007). Keluarga Berencana dan Kontrasepsi. Jakarta: Pustaka Sinar Harapan.

Hurlock (2009). Psikologi Perkembangan Suatu Pendidikan Sepanjang Rentang Kehidupan. Edisi kelima. Jakarta. Erlangga. 
Manuaba (2010). Ilmu Kebidanan, Penyakit Penyakit Kandungan dan Keluarga Berencana. Jakarta: EGC

Mubarak (2010). Promosi Kesehatan untuk Kebidanan. Jakarta: Salemba Medika.

Notoatmodjo (2006). Metodologi Penelitian Kesehatan. Jakarta: Renika Cipta.

Pinem (2009). Kesehatan Reproduksi dan Kontrasepsi. Jakarta: Trans Info Media.

Sarwono (2007). Ilmu Kandungan. Jakarta: Yayasan Bina Pustaka.

Suratun, dkk (2008). Pelayanan Keluarga Berencana dan Pelayanan Kontrasepsi. Jakarta: Trans Info Media.

Wulandari (2013). Hubungan Pendidkan Terhadap Pengetahuan Akseptor KB Dalam Penggunaan KB di Wilayah Kerja Puskesmas Pasar Ikan Kecamatan Teluk Segara. Bengkulu. KTI. Akademi Kebidanan Dehasen.

(2013). Masalah Kependudukan di Indonesia. (Diakses 23 Desember 2015) Diunduh dari :Www://httpprofilkesehatanindonesia.co $\mathrm{m}$ 